\title{
Validation of the PANAS: A Measure of Positive and Negative Affect for Use with Cross-National Older Adults
}

\author{
Sofia von Humboldt ${ }^{1}$, Ana Monteiro ${ }^{1} \&$ Isabel Leal $^{1}$ \\ ${ }^{1}$ ISPA-Instituto Universitário, Lisbon, Portugal \\ Correspondence: Sofia von Humboldt, ISPA-Instituto Universitário, Lisbon, Portugal. Tel: 351-218-81-1700. \\ E-mail: sofia.humboldt@gmail.com
}

Received: December 24, 2016

Accepted: December 27, 2016

Online Published: March 8, 2017

doi:10.5539/res.v9n2p10

URL: http://doi.org/10.5539/res.v9n2p10

\begin{abstract}
Objectives: Positive and negative affect is a relevant facet of well-being for community-dwelling older adults. This article reports the validation of the Positive And Negative Affect Scale (PANAS), by means of confirmatory analysis.

Methods: A community-dwelling cross-national sample of 1291 older adults aged 75 years-old and older voluntarily completed the PANAS. The relations between variables in the model were evaluated using structural equation based on maximum likelihood estimation. The distributional properties, cross-sample stability, internal reliability, and convergent, external and criterion-related validities of the PANAS were analyzed and found to be psychometrically acceptable.

Results: Our results outcomes support for the hypothesis that the PANAS is valid and reliable in the two 10-item mood scales, hence fit for use with older adults, within a culturally diverse view of well-being.

Conclusions: The psychometric properties of the PANAS are satisfactory in this older sample, and according to those of its early version. Taken together, these results substantiate the validity of this measure when applied to an older community cross-national population.
\end{abstract}

Keywords: older adults, psychometric properties, positive and negative affect, Positive And Negative Affect Scale

\section{Introduction}

Population aging is developing rapidly in both developed and developing countries. The proportion of the world's population aged 60 and above increased from $8 \%$ in 1950 to $12 \%$ in 2013 and it will rise more rapidly in the next four decades reaching $21 \%$ in 2050 . Globally, the share of old people aged 80 and above, i.e., the oldest old, within the older population was $14 \%$ in 2013 and it is projected to reach $19 \%$ in 2050 (United Nations, 2013).

Old people may have to cope with distinctive physical and mental health challenges. Hence, the aging well of this segment of the population has become a relevant issue for researchers and health professionals (Netuveli \& Blane, 2008).

Older adults face distinct physical and mental health challenges which need to be highlighted. Hence, aging well of the older people has become a pertinent matter for researchers and health professionals.

Preserving a high Subjective Well-Being (SWB) is considered to be a relevant aspect of successful aging (Baltes \& Baltes, 1990).

Positive Affect (PA) and Negative Affect (NA) have been used as general dimensions to describe affective experience, and they are the affective, emotional components of SWB (Diener, Emmons, Larsen, \& Griffin, 1985). PA reflects the extent to which a person feels enthusiastic, excited and active. Increased levels of PA indicate a state of full concentration, pleasurable engagement and high energy, and, whereas low levels of PA suggest lethargy and sadness. In contrast, NA is a general dimension of unpleasurable engagement and subjective distress, that includes a variety of mood states, such as guilt, anger or disgust (Cotigă, 2012). Low levels of NA show a state of tranquillity and calmness (Watson, Clark, \& Tellegen, 1988). Additionally, affect 
balance refers to the equilibrium of the positive and negative feelings experienced by the individual (Pinqüart, 2001).

Pinqüart (2001) suggested that older adults may feel lower levels of PA and higher levels of NA than their younger counterparts, due to age associated decrease of gains and increase of losses. PA may be a protective element, acting as a negative risk factor for disease and cognitive incapability (Krijthe et al., 2011), and it is associated with better individual functioning (Fredman, Hawkes, Black, Bertrand, \& Magaziner, 2006), less adjustment problems, less chronic pain (Sturgeon, Zautra, \& Arewasikporn, 2014) and better general health (Pressman \& Cohen, 2005). Losses, such as the death of a spouse or other social companions, and role losses, such as the ones related to retirement may contribute to the unbalancing of PA and NA (Chatters, 1988). Indeed, previous research showed an age-associated decrease in the frequency of social and non-social activities, which may reduce the level of PA (Hilleras, Jorm, Herlitz, \& Winblad, 1998).

The Positive And Negative Affect Schedule (PANAS) was designed by Watson and his colleagues (1988) for evaluating positive and negative affect. The PANAS has been validated in various cultures and in different languages around the world (e.g., Chilean, English, Estonian, German, Hungarian, Japanese, Portuguese, Romanian, Russian, Spanish, and Turkish) and the results have consistently shown good psychometric properties (Carvalho et al., 2013; Cotigă, 2012; Crawford \& Henry, 2004; Dufey \& Fernandez, 2012; Galinha, Pereira, \& Esteves, 2014; Gyollai, Simor, Koteles, \& Demetrovics, 2011; Pires, Filgueiras, Ribas, \& Santana, 2013; Sandín et al., 1999; Terracciano, McCrae, \& Costa, 2003). Currently, different versions of this measure are available, such as an extended and a shorter version compared to the original PANAS (e.g., Cotigă, 2012; MacKinnon et al., 1999), and one for children (e.g., Huebner \& Dew, 1995; Crawford \& Henry, 2004). Several versions of the PANAS have also been validated for Portuguese-speaking samples (Carvalho et al., 2013; Galinha, Pereira, \& Esteves, 2014; Galinha \& Pais-Ribeiro, 2005; Pires, Filgueiras, Ribas, \& Santana, 2013), with good psychometric properties, and these reliably measured two distinct dimensions (PA and NA), based on the earlier work by Watson and his colleagues (1988). Additionally, previous research revealed some validations of the PANAS among small older samples (Albuquerque, Sousa, \& Martins, 2010; Buz, Pérez-Arechaederra, Fernández-Pulido, \& Urchaga, 2015; Nolla, Queral, \& Miró, 2014). Thompson (2007), and Terracciano and his colleagues (2003) reported the validation of different versions of PANAS using informants from a range of cultural backgrounds. However, thus far no studies have validated the PANAS in a cross-national older sample. Hence, the main objectives of this research are to analyze the validation of the PANAS, by means of confirmatory analysis in a cross-national community-dwelling sample of older adults. To do so, this study will analyze construct validity, criterion and external-related validities, and reliability of the PANAS in the used sample.

\section{Methods}

\subsection{Participants}

In brief, 1291 older participants aged 75 years old and older living in the community were recruited. Table 1 shows the characteristics of the cross-national older sample. Participants ranged in age from 75 to 102 years old, (Mean) $M=83.9$, (Standard Deviation) $S D=6.68$. This sample was mostly composed by women $(58.2 \%)$ and Caucasian (73\%). Fifty-six percent indicated that they were married and $51.9 \%$ reported to be professionally inactive. Participants received no response incentive for this study.

Table 1. Socio-demographic sample characterization

\begin{tabular}{lcc}
\hline Characteristics & $N$ & $\%$ \\
\hline Participant's Gender & 540 & 41.8 \\
Male & 751 & 58.2 \\
Female & & \\
Participant's Household's Annual Income & 640 & 49.6 \\
$\leq 10,000 €$ & 651 & 50.4 \\
$\geq 10,001 €$ & & \\
Participants' Educational Attainment & 1082 & 83.8 \\
Finished High School & & \\
\hline
\end{tabular}




\begin{tabular}{lcc}
\hline Unfinished High School & 209 & 16.2 \\
Participant's nationality & 285 & \\
Angolan & 314 & 22.1 \\
Brazilian & 341 & 24.3 \\
English & 351 & 26.4 \\
Portuguese & & 27.2 \\
Participant's Marital Status & 725 & \\
Married or remarried & 566 & 56.2 \\
Single or widowed & & 43.8 \\
Participant's Professional Involvement & 670 & \\
Not professionally involved & 621 & 48.9 \\
Professionally involved & & 48.1 \\
\hline
\end{tabular}

\subsection{Material}

The PANAS is a globally used affect scale and it asks the respondent about his or her emotional state, concerning ten positive and ten negative emotions using a five-point scale, from: (1) "Very slightly or not at all" to (5) "Extremely". Its psychometric properties indicated good reliability with a Cronbach's alpha of .88 for PA, and .87 for NA. A variety of time frames may be used with the PANAS, but in the current study the time frame employed was "in the past month" (Watson et al., 1988).

The sense of coherence was measured by the Orientation to Life Questionnaire (OtLQ) (Antonovsky, 1993). The OtLQ is a specific multi-item measure of sense of coherence and its frequency, using a seven-point scale: (1) "Never" to (7) "Always", which showed a Cronbach's alpha of .82 (Antonovsky, 1993).

The Satisfaction with Life Scale (SwLS) intends to measure perceived satisfaction with life on the basis of person-specific criteria. The SwLS shows five separate questions, with seven response alternatives from (1) "Strongly disagree" to (7) "Strongly agree". Its psychometric properties indicated good reliability with a Cronbach's alpha of .78 (Diener et al., 1985).

The Adjustment to Aging Scale (AtAS) intends to evaluate adjustment to aging, with 22 different items, and seven response alternatives measuring its importance from (1) "Not important at all" to (7) "Absolutely important". Its psychometric properties indicated good reliability with a Cronbach's alpha of .89 (von Humboldt, Leal, Pimenta, \& Maroco, 2013).

\subsection{Procedure}

We invited older adults to participate in a study about their emotions in old age. The older adults who volunteered completed anonymously, ethically and freely the informed consent, a cognitive screening assessment and the questionnaires in the time frame of 45 minutes. The researcher was present to answer any questions and all questionnaires were maintained in a protected location.

For the purpose of this study, participants must have been aged 75 years-old and older, have scored a minimum 26 in the cognitive assessment of the MMSE (Folstein, Folstein, \& McHugh, 1975), and have shown no history of psychiatric illness, or drug abuse.

This study was undertaken with full approval from the he William James Center for Research, from ISPA -Instituto Universitário and the Portuguese Foundation for Science and Technology (FCT).

\subsection{Psychometric Analysis}

A Confirmatory Factor Analysis (CFA) was used to determine the factor structure of our dataset, and hence construct validity.

We used the following statistics: Comparative Fit Index $(C F I)$, chi-square $\left(X^{2} / d f\right)$, Root Mean Square Error of Approximation (RMSEA) and Goodness of Fit Index $(G F I)$ for assessing the goodness of fit of the measurement model (Byrne, 2001; Hu \& Bentler, 1999; Maroco, 2010). We employed the Average Variance Extracted (AVE) for testing the convergent validity of the PANAS. Additionally, we compared the interfactors' squared correlation with the AVE of each individual factor, to assess discriminant validity (squared correlation between 
factors $<$ individual factor AVE). We used Pearson's correlation with AtAS, SwLS and OtLQ for exploring criterion validity (Fornell \& Larcker, 1981; Maroco, 2010).

The original sample was divided in two groups, randomly selected $(60 \%$ and $40 \%$ of the total sample) for running a CFA.

To establish external validity, the factor weights and relations stability were evaluated in $40 \%$ of the sample and CFA was performed in $60 \%$ of the sample (Maroco, 2010).

Minimum and maximum values, mean, kurtosis and skewness were appraised within distributional properties. The Cronbach's alpha was used for assessing internal consistency (Maroco, 2010).

\section{Results}

\subsection{Construct Related Validity}

\subsubsection{Confirmatory Factor Analysis}

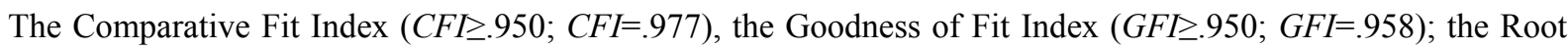
Mean Square Error of Approximation (RMSEA $\leq .050$; RMSEA=.043), and the full $90 \%$ confidence interval for the RMSEA were each within ideal limits for this model [.039<RMSEA $\left.\mathrm{CL}_{90}<.047\right]$. In brief, the positive and negative affect measurement model presented a good fit $\left(X^{2} / d f=3.369 ; C F I=.977 ; G F I=.958 ; R M S E A=.043\right.$; $p=.999 ;$ C.I. $90 \%=[.039 ; .047])$.

\subsubsection{Convergent Validity}

Convergent validity was shown since the scales which were expected to correlate, were demonstrated to be correlated (AVE scores $>$.450).

Table 2. Convergent validity, reliability and discriminant validity for the Positive Affect and Negative Affect Scale

\begin{tabular}{lccc}
\hline Positive Affect and Negative Affect Subscales & AVE & Cronbach's Alpha & Squared correlations \\
\hline Positive Affect & .573 & .922 & \\
Negative Affect & .442 & .884 & .076 \\
Positive Affect - Negative Affect & & & .076 \\
\hline
\end{tabular}

\subsubsection{Discriminant Validity}

Discriminant validity was shown since it was demonstrated to be possible to discriminate between the constructs that were expected not to relate (squared correlation between factors $<$ individual factor AVE) (see Table 2).

In brief, these analyses demonstrate the convergent and discriminant validity of responses to the PANAS.

\subsection{Criterion Validity}

Divergent criterion validity was demonstrated in the following measures and subscales: AtAS, SwLS and OtLQ. PANAS score was negatively associated with AtAS score $(r=-.099 ; p<.001)$, and positively associated with SwLS score $(r=.092 ; p=.001)$ and with OtLQ score $(r=.258 ; p<.001)$.

PA was positively correlated with comprehensibility $(r=.086 ; p=.002)$ and with manageability subscale $(r=.072$; $p=.009)$ and it was negatively correlated with sense of purpose and ambitions subscale $(r=-.167 ; p<.001)$, with social support subscale $(r=-.084 ; p=.003)$, with zest and spirituality subscale $(r=-.269 ; p<.001)$, with aging in place and stability subscale $(r=-.240 ; p<.001)$ and with body and health subscale $(r=-.118 ; p<.001)$. NA subscale was positively correlated with social support subscale $(r=.167 ; p<.001)$, with sense of purpose and ambitions subscale $(r=.119 ; p<.001)$, with zest and spirituality subscale $(r=.130 ; p<.001)$ and with body and health subscale $(r=-.196 ; p<.001)$. Other associations were not significant or inferior in absolute value to the associations encountered.

\subsection{External Validity}

The model presents a good adjustment $\left(X^{2} / d f=2.203 ; C F I=.976 ; G F I=.946 ; R M S E A=.031 ; p=1.000 ;\right.$ C.I. $90 \%=[.028 ; .034])$ in two independent groups. 
External validity indicates the extent to which the results of this study are stable and can be generalized beyond the sample. In our sample, the external validity of the measurement model was demonstrated $\left(X^{2}(18)=18.321\right.$; $p=.435)$.

\subsection{Distributional Properties}

To evaluate the distributional properties, the range of the PANAS measure was assessed. All items showed responses between 1 and 5. The skewness and kurtosis of the 20 items were also assessed. All values of skewness and kurtosis were below 3 and 7 (see Table 3).

Table 3. Minimum and maximum scores, skewness and kurtosis for the Positive Affect and Negative Affect Scale

\begin{tabular}{ccccc}
\hline Items & Minimum & Maximum & Skewness & Kurtosis \\
\hline 1 & 1 & 5 & .344 & -.551 \\
2 & 1 & 5 & .422 & .440 \\
3 & 1 & 5 & .427 & -.396 \\
4 & 1 & 5 & .408 & -.697 \\
5 & 1 & 5 & .121 & -.493 \\
6 & 1 & 5 & .173 & -.1 .001 \\
7 & 1 & 5 & .325 & -.762 \\
8 & 1 & 5 & .139 & -.923 \\
9 & 1 & 5 & .401 & -.835 \\
10 & 1 & 5 & .302 & -.1 .184 \\
11 & 1 & 5 & -.067 & -.951 \\
12 & 1 & 5 & .227 & -.831 \\
13 & 1 & 5 & .427 & -.429 \\
14 & 1 & 5 & .317 & -.738 \\
15 & 1 & 5 & .118 & -.709 \\
16 & 1 & 5 & .273 & -.663 \\
17 & 1 & 5 & .042 & -.766 \\
18 & 1 & 5 & .349 & -.735 \\
19 & 1 & 5 & .089 & -.766 \\
20 & 1 & 5 & .132 & -.630 \\
\hline
\end{tabular}

\subsection{Reliability}

The reliability of the PANAS scale was assessed $(\alpha=.787)$. Additionally, the subscales also showed a very good reliability (see Table 2).

\section{Discussion}

The results of this study contributed to the gerontological literature, by providing considerable psychometric support for the reliability and validity of responses to the PANAS. Therefore, PANAS may be accurately used with older adults in future cross-national interventions in community settings, within a culturally-diverse view of well-being.

The PANAS model showed a good fit in our sample $\left(X^{2} / d f=3.369 ; C F I=.977 ; G F I=.958 ; R M S E A=.043 ; p=.999\right.$; C.I. $90 \%=[.039$; .047]), similarly to previous research (Buz et al., 2015; Nolla, Queral, \& Miró, 2014). Hence, these user-driven outcomes may be applied in combination with other well-being and health-related measures for policy programs and community-based interventions with cultural-diverse old people. This measure has been widely used, as demonstrated by the development and validation of shortened and extended versions, as well as one for children. Unexpectedly, we found a relatively small number of studies on the psychometric properties of 
the measure in cross-national settings (Terracciano et al., 2003; Thompson, 2007), in diverse ethnic groups (Merz et al., 2013), and among older adults (Buz, Pérez-Arechaederra, Fernández-Pulido, \& Urchaga, 2015; Nolla, Queral, \& Miró, 2014). Additionally, thus far no studies have validated the PANAS within a cross-national older sample. Therefore, psychometric information, as well as cultural comparison about this construct is still needed among older samples.

The most debated characteristic of the PANAS is the independence of its factors. The PANAS includes two mood scales intended to assess PA and NA independently. However some discrepancies were found in the literature on the factor structure of the PANAS. These could be attributed to inconsistencies in the used methods or, alternatively, variation in the structure of the PANAS in diverse samples (Crawford \& Henry, 2004).

Our results restated the PANAS as a two-factor and global evaluation of positive and negative affect among an old sample, as demonstrated across diverse age and cultural groups (Gyollai et al., 2011; Merz et al., 2013; Terracciano et al., 2003; Thompson, 2007). In fact, data supported the affective structure proposed by Watson et al. (1988), in which two independent affective dimensions (positive and negative affect) clearly represent distinct moods with their specific content (Crawford \& Henry, 2004; Tellegen et al., 1999).

Divergent criterion validity was demonstrated in the AtAS, SwLS and OtLQ, hence PANAS is assessing a construct distinct from the ones evaluated by these three measures. It might seem counterintuitive that adjustment to aging total score and its subscales were not positively correlated with PA and negatively with NA. We hypothesised this is because positive and negative affect is an appraisal of mood at one point in life (Watson \& Clark, 1992; Watson et al., 1988). Moreover, literature has indicated the relation between PA and extraversion, and between NA and neuroticism in different international samples, hence suggesting a general pattern of associations between affect and personality domains across languages and cultures (e.g., Costa \& McCrae, 1980, 1991; Watson \& Clark, 1992).

The positive and negative affect assessment proved to be stable, considering that the unconstrained measurement model does not suggest a better fit than the model with constrained factorial weights $\left(X^{2}(18)=18.321 ; p=.435\right)$, thus indicating configurational invariance and external validity, i.e., and corroborating previous research (Crawford \& Henry, 2004). Moreover, it must be noted that there is no agreement regarding the stability of SWB in old age (von Humboldt, Leal, \& Pimenta, 2015). Some authors highlighted the positive correlation between age and SWB (Baltes \& Baltes, 1990; Brandstädter \& Greve, 1994; Larson, 1978; Sener, 2011; Stacey \& Gatz, 1991), while other authors stressed the negative correlation between age and SWB (Doyle \& Forehand, 1988).

Lastly, the reliability of the PANAS proved to be good, which is in line with the results found in previous validation studies with old samples (Buz, Pérez-Arechaederra, Fernández-Pulido, \& Urchaga, 2015; Nolla, Queral, \& Miró, 2014).

Our study does have some limitations. One derives from the fact that our sample of older adults is $73 \%$ Caucasian and relatively well-educated. Cultural, educational and ethnic background may affect differently the experience of SWB in diverse older groups.

Selection bias often may have occurred, since our sample did not accurately represent the older population. Although participants were drawn from Europe, comparatively few older adults from minority communities were recruited. Further research is warranted with more minority-specific seniors' representative groups.

The cross-sectional data also restricted psychometric evaluation by the single-point-in-time evaluation. In the present study, the "in the past month" time frame was employed because it is has been one of the most frequently used in previous research (Watson et al., 1988). A longitudinal analysis of these psychometric pointers would allow for an elucidation of the stability of the two 10-item proposed mood scales.

Additionally, all variables were assessed via self-report questionnaire and therefore may be subject to reporting or information bias. Further studies may also investigate whether positive and negative affect is correlated to other personality measures, namely neuroticism, and extraversion in both community-based and clinical older samples.

The large, heterogenous, cross-national sample of 1291 respondents recruited for this study is a definitive strength. These analyses offer strong provision for the reliability and validity of the PANAS in a cultural-diverse older sample, while the statistical analysis was designed to be adequate to current practice in structural equation modeling (Kline, 2005).

The contribution of this psychometric analysis has a great value in future comparisons concerning the well-being of aging populations under diverse cultural conditions, both is developed and in developing countries. Moreover, if the use of the PANAS in research, policies and interventions, is to be optimal then it is indispensable to outline 
its core structure. Further research studies should compare cross-national differences on the perception of affect states in old age.

To conclude, psychometric properties, such as construct, criterion and external validity have been shown to be good for the PANAS. We showed divergent criterion validity and reliability for data gathered in a cross-national large older sample drawn from the general adult population, suggesting that the PANAS is evaluating a construct different from those assessed with AtAS, SwLS and OtLQ.

Our study extends previous work, reiterating the pertinence of assessing the positive and negative affect in community-dwelling cross-national older samples. Considering the need for older adults to live their years with quality, independence and well-being, user-driven measures may be used in interventions in community settings that are still insufficiently responsive to cultural diversity.

\section{Authors' Roles}

$\mathrm{SvH}$ was responsible for the study concept and design, supervised the data collection and analysis and wrote the manuscript. AM made conceptual contributions to the manuscript. IL made conceptual contributions and reviewed the manuscript. All authors read and approved the final manuscript.

\section{Acknowledgements}

This work was supported by the Portuguese Foundation for Science and Technology (FCT), under Grant [grant number SFRH/BD/44544/2008].

Conflict of Interest: The authors report no conflicts of interest. The authors alone are responsible for the content and writing of the paper.

Sponsor's Role: The fund approved the design and aims of the study but did not play any role in the collecting of data, interpretation of results, or preparation of this article.

\section{References}

Albuquerque, F. J. B. D., Sousa, F. M. D., \& Martins, C. R. (2010). Validação das escalas de satisfação com a vida e afetos para idosos rurais [Validation of the satisfaction with life and affects scale in rural older adults]. Psico (Porto Alegre), 41(1), 85-92.

Antonovsky, A. (1993). The structure and properties of the sense of coherence scale. Social Science and Medicine, 36(6), 725-733. https://doi.org/10.1016/0277-9536(93)90033-Z

Baltes, P. B., \& Baltes, M. M. (1990). Psychological perspectives on successful aging: The model of selective optimization with adaptation. In P. B. Baltes, \& M. M. Baltes (Eds.), Successful aging: Perspectives from the behavioral sciences (pp. 1-34). New York: Cambridge University Press. https://doi.org/10.1017/CBO9780511665684

Brandstädter, J., \& Greve, W. (1994). The aging self: Stabilizing and protective processes. Developmental Review, 14(1), 52-80. https://doi.org/10.1006/drev.1994.1003

Buz, J., Pérez-Arechaederra, D., Fernández-Pulido, R., \& Urchaga, D. (2015). Factorial structure and measurement invariance of the PANAS in Spanish older adults. Spanish Journal of Psychology, 3(18), 3. https://doi.org/10.1017/sjp.2015.6

Byrne, B. M. (2001). Structural equation modelling with AMOS: Basic concepts, 280 applications and programming. London, England: LEA.

Carvalho, H. W., Andreoli, S. B., Lara, D. R., Patrick, C. J., Quintana, M. I., Bressan, R. A., ... Jorge, M. R. (2013). Structural validity and reliability of the Positive and Negative Affect Schedule (PANAS): Evidence from a large Brazilian community sample. Revista Brasileira de Psiquiatria, 35(2), 942-949. https://doi.org/10.1590/1516-4446-2012-0957

Chatters, L. (1988). Subjective well-being evaluations among older Black Americans. Psychology and Aging, 3(2), 184-190. https://doi.org/10.1037/0882-7974.3.2.184

Costa, P. T., \& McCrae, R. R. (1980). Influence of extraversion and neuroticism on subjective well-being-Happy and unhappy people. Journal of Personality and Social Psychology, 38, 668-678. https://doi.org/10.1037/0022-3514.38.4.668

Costa, P. T., \& McCrae, R. R. (1991). Revised NEO personality inventory (NEO PI-R) and NEO five-factor inventory (NEO-FFI): Professional manual. Odessa, FL: Psychological Assessment Resources. 
Cotigă, M. (2012). Development and validation of a Romanian version of the expanded version of Positive and Negative Affect Schedule (PANAS-X). Procedia-Social and Behavioral Sciences, 33, 248-252. https://doi.org/10.1016/j.sbspro.2012.01.121

Crawford, J. R., \& Henry, J. D. (2004). The Positive and Negative Affect Schedule (PANAS): Construct validity, measurement properties and normative data in a large non-clinical sample. British Journal of Clinical Psychology, 43(3), 245-265. https://doi.org/10.1348/0144665031752934

Diener, E., Emmons, R. A., Larsen, R. J., \& Griffin, S. (1985). The satisfaction with lifescale. Journal of Personality Assessment, 49, 71-75. https://doi.org/10.1207/s15327752jpa4901_13

Doyle, J. P., \& Forehand, P. R. (1989). Measures of social psychological attitudes. Survey Research Center, Institute for Social Research, Ann Arbor.

Dufey, M., \& Fernández, A. M. (2012). Validez y confiabilidad del Positive Affect and Negative Affect Schedule (PANAS) en estudiantes universitarios chilenos [Validity and reliability of the Positive Affect and Negative Affect Schedule (PANAS) among Chilean university students]. Revista Iberoamericana de Diagnóstico y Evaluación Psicológica, 34(2), 157-173.

Folstein, M. F., Folstein, S. E., \& McHugh, P. R. (1975). Mini-mental state. A practical method for grading the cognitive state of patients for the clinician. Journal of Psychiatric Research, 12, 189-198. https://doi.org/10.1016/0022-3956(75)90026-6

Fornell, C., \& Larcker, D. F. (1981). Evaluating SEM with unobserved variables and measurement error. Journal of Marketing Research, 18, 39-50. https://doi.org/10.2307/3151312

Fredman, L., Hawkes, W., Black, S., Bertrand, R., \& Magaziner, J. (2006). Elderly patients with hip fracture with positive affect have better functional recovery over 2 years. Journal of the American Geriatrics Society, 54(7), 1074-1081. https://doi.org/10.1111/j.1532-5415.2006.00786.x

Galinha, I., \& Ribeiro, J. (2005). Contributions for the study of the Portuguese version of Positive and Negative Affect Schedule (PANAS): II-Psychometric study. Analise Psicologica, 23, 219-227.

Galinha, I., Pereira, C., \& Esteves, F. (2014). Versão reduzida da escala portuguesa de afeto positivo e negativo-PANAS-VRP: Análise fatorial confirmatória e invariância temporal. Psicologia, 28(1), 53-65. https://doi.org/10.17575/rpsicol.v28i1.622

Gyollai, A., Simor, P., Koteles, F., \& Demetrovics, Z. (2011). Psychometric properties of the Hungarian version of the original and the short form of the Positive and Negative Affect Schedule (PANAS). Neuropsychopharmacologia Hungarica, 13(2), 73-79.

Hilleras, P., Jorm, A., Herlitz, A., \& Winblad, B. (1998). Negative and positive affect among the very old: A survey on a sample age 90 years or older. Research on Aging, 20(5), 593-610. https://doi.org/10.1177/0164027598205003

Hu, L. T., \& Bentler, P. M. (1999). Cutoff criteria for fit indexes in covariance structure analysis: Conventional criteria versus new alternatives. Structural Equation Modeling, 6, 1-55. https://doi.org/10.1080/10705519909540118

Huebner, E., \& Dew, T. (1995). Preliminary Validation of the Positive and Negative Affect Schedule with Adolescents. Journal of Psychoeducational Assessment, 13(3), 286-293. https://doi.org/10.1177/073428299501300307

Kline, R. B. (2005). Principles and practices of structural equation modelling. New York: The Guilford Press.

Krijthe, B., Walter, S., Newson, R., Hofman, A., Hunink, M., \& Tiemeier, H. (2011). Is positive affect associated with survival? A population-based study of elderly persons. American Journal of Epidemiology, 173(11), 1298-1307. https://doi.org/10.1093/aje/kwr012

Larson, R. (1978). Thirty years of research on the subjective well-being of older Americans. Gerontology, 33, 109-125. https://doi.org/10.1093/geronj/33.1.109

Mackinnon, A., Jorm, A., Christensen, H., Korten, A., Jacomb, P., \& Rodgers, B. (1999). A short form of the Positive and Negative Affect Schedule: Evaluation of factorial validity and invariance across demographic variables in a community sample. Personality and Individual Differences, 27(3), 405-416. https://doi.org/10.1016/S0191-8869(98)00251-7 
Maroco, J. (2010). Análise de equações estruturais [Structural equations analysis]. Pero Pinheiro: Report Number.

Merz, E. L., Malcarne, V. L., Roesch, S. C., Ko, C. M., Emerson, M., Roma, V. G., \& Sadler, G. R. (2013). Psychometric properties of Positive and Negative Affect Schedule (PANAS) original and short forms in an African American community sample. Journal of Affective Disorders, 151(3), 942-949. https://doi.org/10.1016/j.jad.2013.08.011

Netuveli, G., \& Blane, D. (2008). Quality of life in older ages. British Medical Bulletin, 85, 113-126. https://doi.org/10.1093/bmb/ldn003

Nolla, M., Queral, R., \& Miró, J. (2014). Las escalas PANAS de afecto positivo y negativo: Nuevos datos de su uso en personas mayores [The Positive and Negative Affect Schedule: Further examination of the questionnaire when used with older patients]. Revista De Psicopatología Y Psicología Clínica, 19(1), 15-21. https://doi.org/10.5944/rppc.vol.19.num.1.2014.12931

Pinqüart, M. (2001). Age differences in perceived positive affect, negative affect, and affect balance in middle and old age. Journal of Happiness Studies, 2(4), 375-405. https://doi.org/10.1023/A:1013938001116

Pires, P., Filgueiras, A., Ribas, R., \& Santana, C. (2013). Positive and negative affect schedule: Psychometric properties for the Brazilian Portuguese version. Spanish Journal of Psychology, 16, 58. https://doi.org/10.1017/sjp.2013.60

Pressman, S., \& Cohen, S. (2005). Does positive affect influence health? Psychological Bulletin, 131(6), 925-971. https://doi.org/10.1037/0033-2909.131.6.925

Sandín, B., Chorot, P., Lostao, L., Joiner, T. E., Santed, M. A., \& Valiente, R. M. (1999). Escalas PANAS de afecto positivo y negativo: Validación factorial y convergencia transcultural. Psicothema, 11(1), 37-51.

Sener, A. (2011). Emotional support exchange and life satisfaction. International Journal of Humanities and Social Science, 1(2), 79-88.

Stacey, C. A., \& Gatz, M. (1991). Cross-sectional age differences and longitudinal change on the Bradburn Affect Balance Scale. Gerontology, 46, 76-78. https://doi.org/10.1093/geronj/46.2.P76

Sturgeon, J., Zautra, A., \& Arewasikporn, A. (2014). A multilevel structural equation modeling analysis of vulnerabilities and resilience resources influencing affective adaptation to chronic pain. Pain, 155(2), 292-298. https://doi.org/10.1016/j.pain.2013.10.007

Tellegen, A., Watson, D., \& Clark, L. A. (1999). On the dimensional and hierarchical structure of affect. Psychological Science, 10, 297-303. https://doi.org/10.1111/1467-9280.00157

Terracciano, A., McCrae R. R., \& Costa, P. T. Jr. (2003). Factorial and construct validity of the Italian Positive and Negative Affect Schedule (PANAS). European Journal of Psychological Assessment, 19, 131-141. https://doi.org/10.1027//1015-5759.19.2.131

Thompson, E. R. (2007). Development and Validation of an Internationally Reliable Short-Form of the Positive and Negative Affect Schedule (PANAS). Journal of Cross-Cultural Psychology, 38(2), 227-242. https://doi.org/10.1177/0022022106297301

Von Humboldt, S. (2016). Conceptual and methodological issues on the adjustment to aging: Perspectives on aging well. New York, NY: Springer. https://doi.org/10.1007/978-94-017-7576-2

Von Humboldt, S., Leal, I., \& Pimenta, F. (2015). Sense of coherence, sociodemographic, lifestyle, and health-related factors in older adults' subjective well-being. International Journal of Gerontology, 9(1), 15-19. https://doi.org/10.1016/j.ijge.2014.01.007

Von Humboldt, S., Leal, I., Pimenta, F., \& Maroco, J. (2013). Assessing adjustment to aging: A validation study for the Adjustment to Aging Scale (AtAS). Social Indicators Research [Epub ahead of print].

Watson, D., \& Clark, L. A. (1992). On traits and temperament-General and specific factors of emotional experience and their relation to the 5-factor model. Journal of Personality, 60, 441-476. https://doi.org/10.1111/j.1467-6494.1992.tb00980.x

Watson, D., Clark, L. A., \& Tellegen, A. (1988). Development and validation of brief measures of positive and of positive and negative affect: The PANAS scales. Journal of Personality and Social Psychology, 54(6), 1063-1070. https://doi.org/10.1037/0022-3514.54.6.1063

World Health Organization. (2015). Worls Health Statistics 2015. Geneva: The Author. 


\section{Copyrights}

Copyright for this article is retained by the author(s), with first publication rights granted to the journal.

This is an open-access article distributed under the terms and conditions of the Creative Commons Attribution license (http://creativecommons.org/licenses/by/4.0/). 